Sánchez Rubio, Dionisio.

Doctorando en "Arte: Producción e Investigación", Universidad Politécnica de Valencia, Facultad de Bellas Artes San Carlos. Centro de Investigación Arte y Entorno.

\title{
Interferencias e hibridaciones: prácticas especulativas en el ámbito del diseño gráfico.
}

\author{
TIPO DE TRABAJO:
}

Comunicación.

PALABRAS CLAVE

Diseño Gráfico; Diseño Especulativo; Diseño Crítico; Metahaven.

KEY WORDS

Graphic Design; Speculative Design; Design Criticism; Metahaven.

\section{RESUMEN}

El diseño especulativo se puede utilizar para promover cambios que aún no se han dado o imaginar posibles escenarios que podrían darse desde una perspectiva crítica. En otros campos como la arquitectura la especulación y las propuestas de ficción son aceptadas ya que se les reconoce su capacidad reflexiva sobre futuras condiciones sociales o políticas. En el ámbito del diseño gráfico, este tipo de planteamientos se ven como una devaluación de la profesión ya que no responden a una cuota de mercado determinada, y por lo tanto, no se les reconoce una función pragmática, realista o útil. Metahaven es uno de los estudios de diseño gráfico que más han investigando en ese campo, desarrollando proyectos de investigación crítica y práctica especulativa que cuestionan el status quo profesional y cuyo objetivo es crear un debate sobre determinados temas políticos y sociales. Las prácticas especulativas nos aportan un modelo crítico que debe ser objeto de estudio en el ámbito académico por su capacidad para dar respuesta a las problemáticas sociales contemporáneas.

\section{ABSTRACT}

Speculative design can be used to promote changes that have not yet taken place or imagine possible scenarios which could materialize from a critical perspective. In other fields, such as architecture, speculation and fictional proposals are accepted given that their capacity to reflect on future social or political conditions is recognized. In the field of graphic design, this type of approach is seen as a devaluation of the profession since it doesn't respond to a particular market sector, and therefore, is not recognized as being pragmatic, realistic or useful. Metahaven is one of the graphic design studios which has conducted the most research in this field, developing projects concerning critical research and speculative practice which question the professional status quo with an aim to creating a debate on certain political and social matters. Speculative practices provide a critical model which ought to be study material in academic circles given its capacity to respond to contemporary social problems. 
Índice.

1. Introducción: Ficción y especulación en el diseño.

2. Un lugar menos confortable: Metahaven.

3. La exploración como herramienta de desarrollo.

\section{Introducción: Ficción y especulación en el diseño.}

El diseño especulativo o de ficción puede ser entendido de múltiples formas, por una parte podemos especular sobre algo que todavía no se ha realizado o sobre algo que se puede mejorar; especulamos en un sentido utópico o distópico, es decir, la especulación en el diseño y el diseño de ficción se pueden utilizar para promover cambios que aún no se han dado, o imaginar posibles escenarios que podrían darse desde una perspectiva crítica.

La ficción tiene que ver con la invención, como una forma para imaginar posibles futuros; la especulación en cambio tiene diferentes significados dependiendo del contexto en el que el término se use (el financiero puede ser uno de ellos). Especular, a su vez, tiene que ver con examinar, mirar, reflexionar y hacer suposiciones. La ficción y la especulación en el diseño se pueden utilizar con el fin de propiciar un cambio para mejorar el mundo ${ }^{1}$.

El diseño especulativo tiene que ver con cierto idealismo promovido desde la profesión cuyo fin es ofrecer soluciones innovadoras a los clientes; estás propuestas en muchas ocasiones son rechazadas ya que se ven condicionadas por el contexto - cultural, social $-y$ que, finalmente, no son aceptadas por el cliente. Esta implicación por parte del diseñador y su capacidad de generar propuestas innovadoras rara vez es recompensada por el cliente, de hecho, se asume con cierta normalidad que el diseñador debe presentar diferentes propuestas y que dentro de estas se suele incluir una propuesta más arriesgada y que -independientemente de que sea las solución más adecuada para solucionar un determinado problema -, suele ser descartada.

En otros campos como la arquitectura la especulación y las propuestas de ficción son aceptadas ya que se les reconoce su capacidad reflexiva sobre futuras condiciones sociales o políticas (un claro ejemplo es el trabajo de arquitectos como Archigram, Superstudio, Lebbeus Woods o Future Systems). En el ámbito del diseño gráfico y la publicidad, este tipo de planteamientos se ven como una devaluación de la profesión ya que no responden a una cuota de mercado determinada. Una vez más el modelo de relación imperante hace que la especulación en el diseño no se dé como una práctica convencional. A pesar de ello, esta tendencia se está invirtiendo y muchos estudios de diseño que realizan trabajos comerciales dedican parte de su tiempo en realizar otro tipos de proyectos más allá de lo pragmático, realista o útil.

El diseño especulativo debe ser entendido desde el diseño crítico, una corriente de pensamiento en el diseño que utiliza los métodos del diseño para hacer declaraciones sobre cuestiones sociales, políticas, económicas y culturales, o sobre la propia disciplina. Generalmente el diseño crítico se relaciona o vincula estrechamente con la escritura crítica sobre el diseño, pero el diseño crítico y el diseño especulativo van más allá de la escritura crítica ya que generan mensajes u objetos que evidencian esa crítica a través de lo visual y lo verbal. Incluso estos mensajes u objetos pueden ser considerados como superfluos en un sentido convencional, pero lo realmente importante es que estos "son portadores de significado que afirman su presencia" ${ }^{2}$.

Desde el concepto de autoría en el diseño podemos entender el diseño crítico y las prácticas especulativas ya que ambos comparten dos principios básicos. El primero de ellos es que se originan a partir de la propia iniciativa del diseñador, es una acción que no requiere del encargo de un cliente siendo el diseñador el responsable del tema, contenidos, formas, procesos, materiales, estética y usuarios finales. El segundo principio compartido es la politización del punto de vista del diseñador, es pues el diseñador quien plantea cuestiones que surgen de sus preocupaciones personales por temas referentes a lo social, cultural, económico y geopolítico, "en ambos casos se intenta buscar soluciones alternativas" ${ }^{3}$.

Los temas a tratar por el diseño crítico y las prácticas especulativas son muy diversos: consumo, privacidad, residuos, sexualidad, deuda, tecnología, los media y la globalización, por citar algunos. En ese sentido, el diseño especulativo, las prácticas especulativas y el diseño activista, convergen e incluso se superponen reclamando un papel más activo en la construcción de significados que permitan mejorar la sociedad y al mismo tiempo, provocar una reacción en la profesión y en sus audiencias.

Las prácticas especulativas y de ficción se han desarrollado principalmente en el ámbito del diseño de producto gracias al trabajo de diseñadores como Anthony Dunne y Fionna Raby, y sus textos Speculative Everything. Design, Fiction, and Social Dreaming, o Hertzian 
Tales Electronic Products, Aesthetic Experience, and Critical Design, que han permitido definir un marco teórico entorno al tema gestado en el ámbito académico (Royal College of Arts en Londres, Media Lab en Bostón, o Sandberg Institute en Amsterdam).

Desde la disciplina del diseño gráfico es más difícil localizar este tipo de prácticas, el diseñador gráfico se encarga de vender los objetos producidos por el mercado capitalista y, debido a ello, su margen de maniobra es inferior, lo que imposibilita la creación de vías alternativas desde dónde construir un discurso crítico.

\section{Un lugar menos confortable: Metahaven.}

Uno de los estudios de diseño gráfico que más han investigando en el diseño especulativo es Metahaven. Formado por Daniel Van Der Velden y Virca Kruk, además de desarrollar proyectos de investigación crítica, la práctica especulativa también forma parte de su trabajo. Estos proyectos de diseño especulativo tienen como objetivo crear un debate sobre temas políticos y sociales; los proyectos se desarrollan íntegramente pero en muchas ocasiones no llegan a utilizarse y quedan en una etapa previa a su materialización, lo que Daniel Van Der Velden denomina "proto-funcional". Las propuestas de identidad visual para "Sealand" (2003-2004) y "Wikileads"4 (2010-2011) ilustran a la perfección de qué manera se puede especular en el diseño gráfico. Ambos proyectos fueron desarrollados íntegramente y seleccionados cuidadosamente por las implicaciones políticas que envuelven tanto al Principado de Sealand como las actividades de Wikileads con Julian Assange. Las identidades visuales finalmente no fueron implementadas pero permitieron el desarrollo de un trabajo de investigación así como la edición de diferentes ensayos y publicaciones sobre el resultado de la misma.

Otro de sus proyectos especulativos es Black Transparency: The Right To Know In The Age Of Mass Surveillance ${ }^{5}$ (2013), una exposición que tuvo lugar en el centro Bureau Europa en Maastricht (Holanda). La exposición es el resultado de una investigación que estudia cómo se organiza la información a nivel mundial y cómo los gobiernos y empresas controlan esta información bajo una supuesta transparencia. Parte de la investigación cuenta con varios ensayos escritos por Metahaven que fueron publicados en la revista e-flux durante los años 2012 y 2013. En ellos se analiza el concepto de Cloud Computing o computación en la nube - como un sistema de almacenamiento que permite un mayor control de nuestros datos -, el desarrollo de la súper-jurisdicciones como un instrumento que legitima a los gobiernos para ejercer la vigilancia, y las relaciones que se dan entre Google y los gobiernos para ejercer un control hegemónico sobre la información. El proyecto especulativo consiste en la traducción visual de todas estas ideas.

De la misma forma opera Facestate (2011), un proyecto de investigación especulativa sobre la relación entre las redes sociales y el estado, sobre como los políticos elogian la iniciativa empresarial de Mark Zuckerberg, sobre el control de las redes sociales, sobre la falsa democracia en red y sobre como los gobiernos utilizan Facebook para vigilarnos. A través de objetos, prototipos, bocetos y piezas gráficas Metahaven construye Facestate, un mundo en el que para el gobierno todos somos un teléfono inteligente, es por ello que casi todas estas piezas son teléfonos inteligentes de plexiglás y otros elementos como pasaportes o teclados. Uno de los teléfonos expuestos es una plataforma que contiene tántalo, un polvo extraído del Congo y que utilizan la mayoría de los teléfonos inteligentes. Otros teléfonos tienen forma de máscara. Estas máscaras, que representan nuestra capacidad para ocultar nuestra identidad o utilizar seudónimos en las redes sociales, son una crítica a las políticas de la compañía sobre el uso de un nombre real a la hora de registrarnos en Facebook. En el suelo del espacio expositivo aparece una retícula de puntos negros que hace referencia a No-Stop City, una propuesta del grupo de arquitectura radical italiana Archizoom realizada en 1969. Esta retícula representa la distribución igualitaria y horizontal de los servicios y es considerada como una de las obras más representativas de la arquitectura radical junto con II Monumento Continuo de Superstudio. No-Stop City contiene dos ideologías a la vez, por una parte es radicalmente comunista e igualitaria, y, al mismo tiempo, radicalmente consumista; el consumo y la producción existen en el mismo espacio y al mismo tiempo ${ }^{6}$. Esta visión de No-Stop City es utilizada por Metahaven como una metáfora de lo que hoy sería la nube: Grid Computing. En Facebook también se dan al mismo tiempo dos ideas contradictorias, el control al que nos somete y la supuesta libertad de expresión que nos ofrece.

Las prácticas especulativas se extienden a lo largo de gran parte del trabajo de Metahaven, Anonymous Fantasy Online Identity (2015) es un proyecto realizado en colaboración con el Walker Art Center de Minneapolis en el que plantean desarrollar cinco identidades visuales para compradores anónimos que quieren construirse una identidad virtual en las plataformas y redes sociales más extendidas. La identidad se crea a partir de las imágenes, deseos y sueños de los compradores. Metahaven a partir de este material creará una identidad visual hecha a su medida.

\section{La exploración como herramienta de desarrollo.}

Las investigaciones de Metahaven ponen de relieve la importancia de la investigación y de la exploración como herramientas de desarrollo en el ámbito del diseño gráfico. Sus investigaciones se basan en el "qué pasaría si", un territorio cada vez menos explorado y por lo tanto más interesante que la investigación aplicada. La investigación en el diseño en la actualidad solo responde a la aplicabilidad de los resultados de la misma, su compromiso social se ciñe a la viabilidad económica y la producción de beneficios a corto plazo. 
Metahaven abre nuevos caminos desde la marginalidad que paradójicamente enraízan con los planteamientos ideológicos de la disciplina, más relacionados con la exploración de las necesidad sociales que en la creación de objetos y comunicados redundantes. Su práctica se sitúa en un lugar no reconocido por la propia profesión, una especie de zona desde donde criticar el status quo en relación a las prácticas y estéticas establecidas ${ }^{7}$. En una era de inestabilidad social, política y económica, los diseñadores deberían hacer más preguntas sobre las diversas problemáticas a las que deberíamos de dar solución.

Se trata de hacer preguntas y construir nuevas ideas para poder reflexionar sobre nuestro papel como constructores de significados. El objetivo de las prácticas especulativas y el diseño crítico es despertar una conciencia crítica en la propia disciplina y en la sociedad en su conjunto, implicando a los múltiples receptores en un diálogo acerca de nuestro lugar en la sociedad (como consumidores y ciudadanos).

Lo realmente importante del trabajo de Metahaven es como desplaza los límites del diseño gráfico, modificando la manera de entender la disciplina. "¿A qué usos sostenibles, aparte de su incuestionable y familiar uso comercial, puede aplicarse el diseño gráfico " $^{8}$. El trabajo de Metahaven podría dar respuesta a la pregunta que planteó Rick Poynor acerca del futuro de la disciplina del diseño

gráfico.

\footnotetext{
1. SUEDA, Jon. All Possibles Futures. London: Bedford Press, 2014, p. 31.

2. MCCARTHY, Steven. The Designer as...: Author, Producer, Activist, Entrepeneur, Curator, and Collaborator: New Models for Communicating. Bis Publishers, 2013, p. 129.

3 . Ibídem, p. 128.

${ }^{4}$. Más información sobre los proyectos en: METAHAVEN. Uncorporate Identity. Lars Müller Publishers, 2010. El Proyecto Sealand Identity está disponible online: METAHAVEN. Sealand Identity Project, 2003 - 2004. [en línea], [consulta: 05/04/14]. http://sealand.janvaneyck.nl/

5. También ha sido expuesta en la galería "Future Gallery" (Berlín). Más información: METAHAVEN. Black Transparency, 2014. [en línea], [consulta: 05/04/15]. http://futuregallery.org/present/metahaven-black-transparency/

${ }^{6}$. HYDE, Andrea. "Metahaven's Facestate Social Media and the State". Walker Art Center, 2011. [en línea], [consulta: 09/05/15]. http://www.walkerart.org/magazine/2011/metahavens-facestate

${ }^{7}$. BRUINSMA, Max. "Off the beaten track". [en línea], [consulta: 26/05/2015]

http://maxbruinsma.nl/index1.html?Jaarboekdesign2011_EN.htm

${ }^{8}$. POYNOR, Rick. No más normas. Diseño gráfico posmoderno. Editorial Gustavo Gili, 2003, p. 171.
}

\section{FUENTES REFERENCIALES.}

COLES, Alex (Ed); ROSSI, Catharine. EP VOL 1: The Italian Avant-Garde 1968-1976. Sternberg Press, 2013.

ERICSON, Magnus, et al. Design Act: Socially and Politicaly Engaged Design Today-Critical Roles and Emerging Tactics. Iaspis, 2011.

ERICSON, Magnus. Iaspis forum on design and critical practice: the reader. laspis, 2009.

MCCARTHY, Steven. The Designer as...: Author, Producer, Activist, Entrepeneur, Curator, and Collaborator: New Models for

Communicating. Bis Publishers, 2013.

POYNOR, Rick. No más normas. Diseño gráfico posmoderno. Editorial Gustavo Gili, 2003.

SUEDA, Jon. All Possibles Futures. Bedford Press, 2014.

VAN DER VELDEN, Daniel; KRUK, Vinca (ed.). Metahaven: Uncorporate Identity. Lars Müller, 2009. 


\section{PUBLICACIONES IMPRESAS:}

GRAPHIC. "When Design becomes Attitude”, Graphic, núm 17, 2011.

METAHAVEN, “Rebrand...or else!”. En: Print magazine, 2011, núm 65.5, p. 81-83.

POYNOR, Rick. "Boderline. Metahaven understakes its own research and makes visual proposal that suggest a new role for graphic design in publiclife". En: Eye magazine. 2009, núm, 71, p. 22-29.

\section{WEBS CONSULTADAS:}

BRUINSMA, Max. "Off the beaten track". [en línea], [consulta: 26/05/2015].

http://maxbruinsma.nl/index1.html?Jaarboekdesign2011_EN.htm

"Graphic Design: Now in Production". Walker Art Center, 2011. [en línea], [consulta: 27/04/15].

http://www.walkerart.org/calendar/2011/graphic-design-now-in-production\#

HYDE, Andre. "Metahaven's Facestate. Social Media and the State". Walker Magazine, 2011. [en línea], [consulta: 26/05/2015].

http://www.walkerart.org/magazine/2011/metahavens-facestate

METAHAVEN. "Captives of the Cloud: Part I". E-flux, 2012. [en línea], [consulta: 27/04/15]. http://www.e-flux.com/journal/captives-ofthe-cloud-part-i/

METAHAVEN. "Captives of the Cloud: Part I". E-flux, 2012. [en línea], [consulta: 27/04/15]. http://www.e-flux.com/journal/captives-ofthe-cloud-part-i/

METAHAVEN. "Captives of the Cloud, Part III: All Tomorrow's Clouds". E-flux, 2013. [en línea], [consulta: 27/04/15]. http://www.eflux.com/journal/captives-of-the-cloud-part-iii-all-tomorrows-clouds/\# ftn31

METAHAVEN." Affiche frontière". Paris Art, 2008. [en línea], [consulta: 27/04/15]. http://www.paris-art.com/exposition-artcontemporain/affiche-frontiere/-metahaven/4415.html\#haut

METAHAVEN. Black Transparency, 2014

[en línea], [consulta: 27/04/15]. http://futuregallery.org/present/metahaven-black-transparency/

PISCITELLI, Alejandro. "Introducción al diseño especulativo: ficción, hackeo y social dreaming". Cátedratos, 2014 [en línea], [consulta: 26/05/2015]. http://catedradatos.com.ar/2014/06/introduccion-al-diseno-especulativo/

PISCITELLI, Alejandro. " El diseño especulativo a mitad de camino entre la crítica textual y el shock (distante) del arte". Cátedratos, 2014 [en línea], [consulta: 26/05/2015]. http://catedradatos.com.ar/2014/06/introduccion-al-diseno-especulativo/

SUEDA, Jon. All Possible Futures, 2014

[en línea], [consulta: 27/04/15]. http://allpossiblefutures.net/

WALKER ART CENTER. Intangibles Anonymous Fantasy Online Identity by Metahaven, 2015. [en línea], [consulta: 26/05/2015]. http://shop.walkerart.org/collections/intangibles/products/online-by-metahaven 